\title{
Reflection on the market operation of the new generation of industrial workers by "dream project"
}

\author{
Liao Yuanbing \\ Heyuan Polytechnic, Heyuan, Guangdong, 517000
}

Keywords: A dream plan, Object, Content, Method

\begin{abstract}
The "dream plan" training project of the new generation industrial workers in Guangdong province is well received by the training object and the public from all walks of life. Since the implementation of the project in 2011, the project has explored a targeted, systematic and scientific training method, train of thought and measures. The project has trained a lot of advantages through the project of a new generation of industrial workers. The key to the implementation of the "dream plan" training project for the new generation industrial workers is to select the target for training, improve the teaching content system and improve the training methods of talents.
\end{abstract}

\section{Introduction}

The new generation industrial workers are the product of the times development, and the quality improvement training for the new generation industrial workers is an inevitable requirement and an urgent task for the development of the times. The implementation of the 'dream plan' training project is a significant measure to solve the problem of the quality improvement training for the new generation of industrial workers

\section{Backgrounds}

The 'dream plan' initiated by the Guangdong Provincial Committee of the Communist Youth League provides a unique platform for the new generation industrial workers to improve their professional quality and skill level, which has a strong epochal and exemplary significance ${ }^{[1]}$. The 'dream plan' of the new generation industrial workers is the product of Guangdong's historical development as the pioneer of reform and opening up. The development of this people's livelihood project has a specific historical background and practical significance.

\subsection{Background of 'dream plan’ implementation}

According to statistics, there are more than 200 million new generation industrial workers in China and more than 30 million new generation industrial workers in the frontier of reform and opening up, Guangdong. The new generation of industrial workers has contributed youth and strength to the social and economic development of Guangdong, and they are an indispensable backbone of the social and economic development of Guangdong. However, the new generation industrial workers are gradually losing their youth when contributing to social and economic development. They have uneven individual comprehensive qualities and uncertain personal development prospects, lack of the competitiveness and strength to survive and develop in society. In the process of obscure and selfless contribution, they urgently need to improve their personal comprehensive quality. In recent years, the core demands of the new generation industrial workers to improve their personal comprehensive quality have been continuously improved. The Guangdong Provincial Committee of the Communist Youth League has discovered this problem and recognized the importance and urgency of upgrading the quality of the new generation industrial workers. So, in 2010, the relevant units jointly launched the 'dream plan - the backbone training project for the new generation industrial workers in Guangdong province’. 


\subsection{Significance of 'dream plan' implementation}

The cause of socialism with Chinese characteristics is a future-oriented cause, and it is necessary for generations of young people with lofty ideals to continue their struggle. The whole party must pay attention to the youth, care for the youth, concern and love the youth, listen to the voice of the youth, and encourage the youth to grow ${ }^{[2]}$. Practice has proved that the implementation of the 'dream plan - the backbone training project for the new generation industrial workers in Guangdong province' has great practical significance, mainly reflected in:

2.2.1 It is an important platform for upgrading the quality of the new generation industrial workers.

At present, the industrial workers of new generation in Guangdong Province present a large scale and low overall quality. Upgrading the quality of the new generation industrial workers has become an urgent task in social and economic development. The implementation of the 'dream plan - the backbone training project for the new generation industrial workers in Guangdong province' is to build an important and good platform to upgrade the quality of the new generation industrial workers.

2.2.2 It is an important way to train the youth backbone of the Communist Youth League

Young people play a large and powerful role in the social and economic development, and the youth backbone training is related to the overall level and future development of the talent training. The new generation industrial workers are an important part of the youth backbone training of the Communist Youth League, and the implementation of the 'dream plan - the backbone training project for the new generation industrial workers in Guangdong province' is an important way and method for the youth backbone training of the Communist Youth League, serving an important project for improving the people's living.

2.2.3 It is an important means of training the new generation industrial workers in colleges and universities.

Colleges and universities are the cradle and base for talent training. Colleges and universities should not only do a good job in full-time schools for talent training, but also continue to educate and build a lifelong education system to train the incumbent of the society. The implementation of the 'dream plan - the backbone training project for the new generation industrial workers in Guangdong province' is an important means of cultivating new generation industrial workers in colleges and universities. This pattern of running schools is favored by the new generation industrial workers in Guangdong.

2.2.4 It is an important measure to maintain and consolidate the foundation of youth governance.

Social stability is a huge systematic project, which includes the stability of the type personnel. Youth is an important part of social development and the most active component. The stability of youth is related to social stability. The stability of youth should be maintained through caring, supporting, and assisting young people to develop. The implement of the 'dream plan - the backbone training project for the new generation industrial workers in Guangdong province' supports the young workers in Guangdong to participate in continuing education and learning, help them develop their growth channels, and promote the economic and social development of Guangdong $^{[3]}$.

The implementation of the project will contribute to the development and progress of the youth, as an important measure to maintain and consolidate the foundation of youth governance. In the context of the new era, the implementation of the 'dream plan - the backbone training project for the new generation industrial workers in Guangdong province' has a more significant significance. In the implementation process, it is necessary to straighten out the market operation mode of the project and clarify the three core issues 'whose dream to come true? What dreams to come true? How the dream comes true?'. 


\section{Whose dream to come true}

The implementation of the 'dream plan - the backbone training project for the new generation industrial workers in Guangdong province' must first clarify the question whose dream to come true, that is, to determine the service target of the project market operation -- the new generation industrial workers, which is the premise and basis for the market operation implementation of this project.

\subsection{Determination of registration conditions}

The 'dream plan - the backbone training project for the new generation industrial workers in Guangdong province' clarifies the requirements of the applicants in the registration conditions: the nationality of the People's Republic of China (including Hong Kong and Macao residents); the age over 18 years old, under 35 years of age (based on July $1^{\text {st }}$ of the current year as the time node); those who are front-line and grassroots employee and have worked for one year; those who apply for junior colleges must have a high school education or above, and those who apply for undergraduate degree need to graduate from a national junior college; physically and mentally health, and compliance with laws and legislation. In addition, the registration system also has given an example for the personnel who are not allowed to apply.

The basic conditions of the registration target determination are required to be the basic framework established by the Guangdong Provincial Committee of the Communist Youth League in implementing the 'dream plan - the backbone training project for the new generation industrial workers in Guangdong province', clarifying the basic objectives of the project service and defining the service object quantitatively and qualitatively. The purpose is to ensure the universality of the project implementation service object.

\subsection{Analysis of applicant objects}

In the process of implementing the 'dream plan - the backbone training project for the new generation industrial workers in Guangdong province', the provincial dream office will allocate the enrollment plan indicators to the local cities according to the scale, demand and previous implementation of the new generation industrial workers. In practice, local cities and towns should conduct in-depth research according to the local industry development and the structure and demand of the new generation industrial workers, and deeply analyze the internal needs of the local new generation industrial workers. The demand groups and internal needs of the new generation industrial workers in the implementation of the 'dream plan - the backbone training project for the new generation industrial workers in Guangdong province’ are understood and grasped through inquiries.

Analyzing the specific situation of the local registered objects in the process of implementing the 'dream plan - the backbone training project for the new generation industrial workers in Guangdong province' is conducive to more targeted development of the project, making the objective of the work clear, pointedly promoting the work and improving the accuracy of the project educational services

\subsection{Fully organizing enrollment}

On the basis of determining the basic conditions of the applicants and analyzing the actual situation of the local new generation industrial workers, the universities and educational institutions that implement the 'dream plan - the backbone training project for the new generation industrial workers in Guangdong province' carry out in-depth enrollment promotion centering on the task of running the school in that year, and make every effort to the enrollment organization. It is necessary to mobilize and organize the qualified new generation industrial workers to actively register through extensive publicity, and actively carry out project propaganda and explanations in enterprises and communities, making more new generations industrial workers understand and participate in the 
project to receive education and improve their quality.

Fully organizing the enrollment work is the performance of the active service in the process of implementing the 'dream plan - the backbone training project for the new generation industrial workers in Guangdong province'. It is a youth education service model that changes passive service to active service and active service, evaluating the universality of the project educational service through extensive publicity, full efforts and meticulous organization.

\section{What dreams to come true?}

The implementation of the 'dream plan - the backbone training project for the new generation industrial workers in Guangdong province' must clarify the question of what dreams to come true, that is, to determine the service content of the project market operation implementation - Making the university dream of the new generation industrial workers comes true is to make the dream of fair education come true ${ }^{[4]}$, which is the focus of the implementation of the project market operation.

\subsection{Determination of running school patterns}

At present, there are two main patterns of the 'dream plan - the backbone training project for the new generation industrial workers in Guangdong province'. One is the adult college entrance examination and the other is online education. Both two education patterns are national education, the difference reflected in: First, the timing is not the same. The online education of the dream project is scheduled to start from July to end in October each year, while the adult college entrance examination is started in July and applied in September, registered for admission in January after the year. Second, the patterns of admission are different. The students taking part in the adult college entrance examination need to pass the national unified examination for admission, while the online education provide admission through the entrance examination organized by the university self. Third, the learning styles are different. Adult college entrance examination is a combination of face-to-face teaching and self-study, while online education is mainly based on online learning. Fourth, one of the graduation certificates states adult higher education and the other one notes online education. Besides, some regions choose the educational pattern of radio and television universities.

In the implementation of the 'dream plan - the backbone training project for the new generation industrial workers in Guangdong province', local youth league committees and organizers need to analyze the advantages and disadvantages of various education patterns, and according to the actual needs of the new generation industrial workers to choose the education pattern.

\subsection{Colleges and universities determination}

At present, the cooperative colleges of the 'dream plan - the backbone training project for the new generation industrial workers in Guangdong province’ include comprehensive key undergraduate colleges inside and outside the province, such as Peking University, Renmin University of China, South China Normal University, Shenzhen University, etc., provincial ordinary universities and colleges, such as Dongguan Polytechnic Institute, Guangdong Finance College, Shaoguan College, Zhongkai Agricultural Engineering College, etc., and provincial high vocational colleges and universities, such as Dongguan Vocational and Technical College, Foshan Vocational and Technical College, Heyuan Vocational and Technical College, etc., and National Open University, Foshan Open University, Shantou Radio and Television University and other radio and television universities.

The election of colleges and universities in the 'dream plan - the backbone training project for the new generation industrial workers in Guangdong province' first should consider the category attribute of colleges and universities and must meet the local needs; second, it needs to consider the popularity and influence of the colleges and universities; third, it should be adjusted to local conditions and have operability and feasibility in propaganda, implementation and management. 


\subsection{Determination of school levels}

There are two levels of running school in the 'dream plan - the backbone training project for the new generation industrial workers in Guangdong province’: The first one is junior colleges starting from high schools and technical secondary schools, and the application condition is that the new generation industrial workers must have a high school or technical secondary school diploma. The second one is undergraduate universities starting from junior colleges, of which the application condition is that the new generation industrial workers must have got a national junior college diploma. It can be seen from the practice of many years, that generally the demand for junior colleges from the new generation industrial workers is greater than the demand for undergraduate universities, while the demand for undergraduate in developed regions is greater than that in underdeveloped regions.

In the process of implementing the 'dream plan - the backbone training project for the new generation industrial workers in Guangdong province', all localities should select and determine the school level according to the talent team of the new generation industrial workers and their demand, following the selection of school level prioritized junior colleges and supplemented by undergraduate universities. At the same time, according to the change of the talent team, undergraduate education will be vigorously promoted. Through the organic combination of junior and undergraduate education, all levels of talents in all aspects are cultivated.

\subsection{Determination of school majors}

In response to the actual needs of the new generation industrial workers, the 'dream plan - the backbone training project for the new generation industrial workers in Guangdong province' has a wide range of majors, basically meeting the requirements of the new generation industrial workers in different fields and types. But there are two main types of majors: the first one is the economic management majors, among which accounting, business administration, and administrative management are demanded most. The second is the mechanical and electronic and computer majors in science and engineering, including the majors of mechatronics, application of electronic technology, computer application technology, etc.

In the process of implementing the 'dream plan - the backbone training project for the new generation industrial workers in Guangdong province', all localities should select and determine the school majors according to the talent structure of the new generation industrial workers and their demand, following the industry-oriented and demand-oriented principles to select the school majors, to cultivate the urgently needed talents for the local social and economic development and industrial transformation and development.

\section{How the dream comes true?}

The implementation of the 'dream plan - the backbone training project for the new generation industrial workers in Guangdong province' must also clarify the question of how the dream comes true, that is, to determine the service method for the implementation of the project market operation -- adult continuing education mode, which is the key for the implementation of the project market operation.

\subsection{Collaborative innovation cooperation}

The implementation of the 'dream plan - the backbone training project for the new generation industrial workers in Guangdong province' should make full use of the resources of local league committees, host universities or educational institutions, and integrate human, finance and material resources to collaboratively carry out the adult continuing education of the project. The local Youth League committees, universities, and educational institutions must establish a linkage mechanism, a division of labor mechanism, and a cooperation mechanism to strengthen the responsibility of the school and the implementation of tasks, forming a joint effort to promote the project 
implementation.

In actual operation, the local league committees should change the phenomenon of only exerting administrative functions and not actively participating in the specific teaching implementation and management process. They are required to initiatively and actively integrate the resources of the group into the project to run well the school; The host universities or educational institutions need to change the inadequacy of separately organizing and implementing teaching, and actively strive for and integrate the working resources of the league committee youth for teaching and talents training.

In addition, the implementation of the 'dream plan - the backbone training project for the new generation industrial workers in Guangdong province’ should pay high attention to mobilizing the enthusiasm of enterprises. The new generation industrial workers are at the grassroots level and frontline of the enterprise. Time schedule, financial support, development guarantee and so on of their participation in the study, need the support from enterprises. It is necessary to enhance the understanding of the importance of the project implementation from the perspective of talents training in the whole society; to enhance the awareness of the significance of the project to the development of the company enterprises from the perspective of the stability of the enterprise workforce; to understand the value of the project from the perspective of improving the personal comprehensive quality of employees.

\subsection{Reform of routine teaching}

The 'dream plan - the backbone training project for the new generation industrial workers in Guangdong province' should not only follow the existing educational policies and rules of the adult continuing education, but also combine with the reality of the new generation industrial workers to reform the routine teaching. It is necessary to reform the teaching plan according to the characteristics and realistic needs of the new generation industrial workers, so as to make the teaching plan more targeted and applicable; to reform the curriculum content system so that the teaching content is more in line with the reality of the new generation industrial workers; to promote the teaching mode of combining theoretical teaching with practical teaching, facilitating the new generation industrial workers to enhance their knowledge and improve their skills; in particular, to blend the reality of local industry development in the implementation of teaching.

In practice, whether the 'dream plan - the backbone training project for the new generation industrial workers in Guangdong province' choses the adult college entrance examination or online education, the teaching reform must be carried out. It cannot blindly follow the routine adult continuing education to implement teaching and should organically combine the face-to-face teaching of the adult college entrance examination and the online learning of online education together, to promote teaching reform, improve the operability and pertinence of teaching implementation, and improve the education quality.

\subsection{Management of innovative students}

In the implementation of the 'dream plan - the backbone training project for the new generation industrial workers in Guangdong province', student management must be performed well. The new generation of industrial workers is first of all workers, living people, and learners, whose burden on their body is very heavy, with uneven cultural levels and diverse characters and personality. The characteristics of this group determine the complexity and the arduousness of the student management of the new generation industrial workers. Therefore, the implementation of he 'dream plan - the backbone training project for the new generation industrial workers in Guangdong province' must innovate the methods of student management and improve the management level and scientificity.

On the one hand, it is needed to set up a teacher management team composed of host universities, educational institutions and local youth league committees and to strengthen all-round management, instruction and guidance; On the other hand, it is necessary to give full play to the students self-management ability, and build up a class committee to implement student 
self-management, improving the management ability of the students through class management. The innovative 'dream plan - the backbone training project for the new generation industrial workers in Guangdong province' should establish a sound management system for student management and strengthen the system to manage people; create a good atmosphere for management and enhance cultural education; optimize the management processes in practice exploration and strengthen the management technology upgrading, to improve the management efficiency and level.

\subsection{Innovation of training methods}

The implementation of the 'dream plan - the backbone training project for the new generation industrial workers in Guangdong province' not only need to carry out routine teaching reform and innovative management through collaborative innovation to train new generations industrial workers, but also need to actively and initiatively innovate training methods, cultivating talents in a variety of forms and broadening the training channels. For example, by means of organizing the new generation industrial workers to participate in exchange visits, their industry awareness is deepened; Their social skills can be enhanced by organizing extracurricular activities; The backbone talents are trained through backbone training classes, play a leading role of the backbone; The entrepreneurial ability and employability of the new generation industrial workers will be improved by youth entrepreneurship and employment training, etc.

The innovation of the training methods in the 'dream plan - the backbone training project for the new generation industrial workers in Guangdong province' is an important means to improve the education quality. Moderation is to be achieved in practice. It is not only necessary to consider the importance and necessity, but also need to prevent the new generation industrial workers from tired participation and walking through the school work, and as well as to prevent some formalized and ineffective learning activities to enhance the learning effect and efficiency.

\section{Conclusion}

The implementation of the 'dream plan - the backbone training project for the new generation industrial workers in Guangdong province' is the requirement of industry transformation and upgrading in Guangdong Province and the actual demand of the numerous new generation industrial workers. The implementation of the project market operation should do a good job in enrollment registration, teaching implementation, student management and other work, improve the level of the work carried out in each link, promote the overall level of the project, and better play the value and role of this significant people's livelihood project.

\section{Acknowledgements}

This paper is to carry out the training of new generation industrial workers for the research projects of Guangdong Provincial Adolescent Education Association from 2018 to 2019, the research and Practice on the growth and development path of new generation industrial workers (2018 GJ060) and the adult education and scientific research program of Guangdong Provincial Adult Education Association (2018-2019). Research and Practice (Ycx181001) research results.

\section{References}

[1] Yang Danyu, New Generation Industrial Workers'Dream-fulfilling Plan and Its Perfecting Path [J], Journal of Dongguan Institute of Technology, 2014 (02): 121-124

[2] Che Ming Dynasty, Guangdong Dream Realization Plan: Making the Dream Bearing Development Write a Chinese Chapter for Life [J], China Vocational and Technical Education, 2013 (04): 17-24 
[3] yuezong, 100 young workers from Guangdong graduated from Peking University, [J], Chinese staff education, 2014 (02): 32

[4] Liu Yao, what dream has the dream come true? [J], education and occupation, 2012 (07): 26 